\title{
High-frequency Trading - to Regulate or Not to Regulate-That is the Question? Does Scientific Data Offer an Answer?
}

\section{Tor Brunzell*}

University School of Business, Stockholm University, Sweden

\section{Introduction}

High-frequency trading (HFT) certainly captures public (and regulatory) attention. On May $6^{\text {th }} 2010$, the Dow Jones (DJ) experienced its largest intraday point drop in history, shedding $\$ 1$ trillion of its market value in half an hour. Largely as a consequence of the eventnamed Flash Crash-regulatory authorities sharpened the regulations concerning HFT: in the U.S., circuit breakers were introduced [1], and the European Union made regulative changes that require equity orders to delay for at least half a second. Also, in the markets, there has been a demand for introducing a financial transactions tax (FTT) in order to discourage high frequency trading.

So, what is high-frequency trading? And why should it be regulated? And if it is regulated, how should that regulation be designed? In this editorial article, I will focus on existing scientific evidence on how HFT affects the market, and on the big questions about HFT that remain unanswered.

\section{What is High-frequency Trading (HFT)?}

Though the first electronic exchange (NASDAQ) was introduced in 1971, it wasn't until the late 1990s that major exchanges started transmitting orders electronically (instead of via telephone, mail, or in person). Today, basically all exchanges have electronic limit order books [2]. Electronic trading advantaged the market by reducing frictions and costs of trading. Algorithmic trading is triggered by a collection of words assayed by computer programs. The algorithmic response is predicated on the abundance and frequency of trigger words identified in trading orders entering the market. These systems are not necessarily fast. High-frequency trading (HFT) is a special form of algorithmic trading, where computers make order decisions depending on the pattern of the information received by the computer. With HFT the computer is programmed to initiate orders depending on models that are extremely fast, where the program attempts to exploit tiny differences in share prices in and between markets. To this purpose, the HFT firms carry out millions of minute, expeditious transactions, each providing a small profit. These mercurial transactions result in one of the differences between HFT differ and regular investments, as often, in HFT, positions are held for just a few seconds, or fractions of a second. Consequently, high frequency computer trading allows traders to move in and out of positions, thousands (or tens of thousands) of times a day. Another consequence is that most HFT firms use minimal leverage, do not accumulate positions, and, at the end of each trading day, typically liquidate all positions. Speed is such critical factor that, often, HFT firms relocate their servers as proximate to the servers of the stock exchanges as possible.

Clark [3] reports that in October 2008 one HFT-firm traded over 2 billion shares in a single day, which meant that the firm accounted for over 10 percent of U.S. equity trading volume for that specific day. It is estimated that HFT accounts for two-thirds (perhaps, even threequarters) of equity trading in the US, and about one-third of the equity trading in Europe.

\section{Trading Strategies of HFT firms}

HFT is not a strategy in and of itself but rather a technologically advanced method of implementing certain trading strategies. The purpose of HFT strategies is to exploit short-term market inefficiencies in pricing or temporary liquidity imbalances. HFT utilizes two sources of public information: macroeconomic news announcements [4]; and imbalances in the limit order book [5].

The HFT trading strategies based on computerized quantitative models, which identify the type of financial instruments to buy or sell (typically, stocks, options, or futures), determine quantity, price, time, and place of trades. There are three primary HFT trading strategies:

A. Liquidity-providing strategies use liquidity algorithms to take advantage of a two-sided market, aiming to take advantage of making the bid and ask price. The strategies were facilitated by maker-taker pricing models and have developed into what is called Passive Rebate Arbitrage, due to the rebate exchanges pay to market makers.

B. Statistical arbitrage strategies use trading algorithms to detect and exploit mispricing between correlated securities and markets.

C. Liquidity detection strategies use filter and momentum algorithms to identify stocks that show significant changes in movement and/ or volume in order to second-guess when an investor wants a specific stock.

\section{The Effects of HFT on the Financial Markets}

At the end of World War II, a US stock was held, on average, for four years; in 2008, the average holding time had fallen to approximately two months. In 2011 the stockholding was 22 seconds. With HFT, shares can be sold several times in a single second. With the change in the topology on systematic risk of the financial market, market-analysts talk less about market microstructure [6], and more about market macrostructure [7].

An extensive study by the UK government [8] concluded that the increase in controversial HFT has generally been good for ordinary investors. The study found, however, that the increasing prevalence of computerized trading has the potential to lead to isolated cases of instability in the financial markets. Furthermore, the study stated that

*Corresponding author: Tor Brunzell, University School of Business, Stockholm University, Sweden, Tel: 46-8-161181; Fax: 46-8-6747440; E-mail: TB@fek.su.se

Received December 08, 2012; Accepted December 10, 2012; Published December 11, 2012

Citation: Brunzell T (2013) High-frequency Trading-to Regulate or Not to Regulate-That is the Question? Does Scientific Data Offer an Answer? J Bus \& Fin Aff 2:e121. doi:10.4172/2167-0234.1000e121

Copyright: @ 2013 Brunzell T. This is an open-access article distributed under the terms of the Creative Commons Attribution License, which permits unrestricted use, distribution, and reproduction in any medium, provided the original author and source are credited. 
the available evidence suggests that computer-based trading has several positive effects on the markets, in particular: liquidity has improved, transaction costs have fallen for both private and institutional traders, and the market has become more efficient. The conclusions of the UK government study is, to say the least, surprising, since the scientific data has difficulty showing how HFT has influenced market quality (typically, measured in the terms of liquidity, informational efficiency, and short-term volatility) over time, especially outside the U.S. [9]. [10]:

HFT may be said to have three key effects on the financial markets

A. Increasing volumes of trade have been compressed into smaller segments of time. Haldane claims that change in stock prices is better understood when looked at in terms of volume rather than in time segments. As volume increases per time segment, price discrepancies increase per time segment.

B. Trader strategies are implemented at escalating frequencies. Hendershott and Riordan [11], Brogaard [12], Kirilenko [13], and Hendershott and Riordan [14] find that the orders of highfrequency traders are better informed than the other orders. Highfrequency traders have access to advance information resulting in adverse selection costs.

C. Not only has the speed of the strategic interaction changed, but also, its nature. Computers may obscure short-comings, helping traders find and exploit trading opportunities more quickly and efficiently, resulting in an artificial understanding of market dynamics. I.e., HFT generate profits from trading, itself, rather than from the dynamics of a healthy market $[14,15]$

\section{Potential HFT Risks}

After two incidents (Flash Crash and Knight Capital) that shocked the financial markets, it is obvious that HFT carries risk [16]. Some believe that HFT plays an increasing role in driving instabilities in particular markets. Kirilenko et al. [13] studied the events during the Flash Crash and concluded that high frequency traders did not trigger the Flash Crash, rather, their responses to unusually large selling pressures increased market volatility. Zhang [17] demonstrated that HFT can exacerbate large fluctuations in moments of crisis.

The two most severe risks with HFT are systematic risk and price manipulation:

\section{HFT amplifies systematic risks}

HFT activities may expose financial markets to systemic risks due to technological vulnerabilities (malfunctioning algorithms), selfreinforcing strategies and/or overloaded technical systems. In a speech, [18] explains that stock movements, during abbreviated time intervals, since mid-2000, have begun to show more fat-tailed behavior, suggesting that the market is experiencing increasingly violent fluctuations. The increasing ferocity of market movements directly impacts HFT market maker risk, and that risk is reflected in bid and ask price premiums they charge. Haldane argues that the risk the market maker takes can effect value and undercut the value traditionally gathered from superior information about true prices. He also concedes that these risks are likely to increase over time.

\section{Price manipulation}

Financial markets rely on accurate pricing of risk. And financial regulation relies on an accurate reading of markets. If market prices are directly affected by HFT, then, accurate pricing of risk and accurate market readings are complicated by HFT. Of course, accusations of unfair advantage resulting from unfair strategies are as old as the market, itself.

\section{The HFT strategies most often mentioned include:}

- Quote stuffing, the strategy of initiating a large volume of orders to a market, then, cancelling them within milliseconds with, the intention of slowing down the trading systems and profiting from the price differences.

- Smoking/layering, the strategy of entering fake trades with the intention of manipulating the price of an instrument and misleading other market participants.

- Momentum ignition, the strategy of initiating or enhancing a trend by aggressively placing orders in the hope that others will follow, and then, in milliseconds, turn their positions.

- Last second withdrawal, the strategy of cancelling orders at the final second of a call procedure.

It should be noted that in the previously mentioned U.K. government study, in the final report, it was concluded that there is "no evidence that high-frequency firms have been able to manipulate the prices of shares for their own benefit." The report argues that "the rise of high-speed trading may be helping to prevent price manipulation because the firms have an incentive to find aberrations in the prices of stocks and quickly force prices to proper market levels." However, it should also be noted that the SEC as well as the London Stock Exchange have handed down fines to HFT firms for price manipulations.

\section{Regulations to Limit the HFT}

Nobel prize winner Paul Krugman [19] argues that HFT has a negative effect on national wealth, and professor Krugman claims that HFT should be accompanied by more regulations, arguing that: "It's hard to imagine a better illustration [of social uselessness] than high frequency trading. The stock market is supposed to allocate capital to its most productive uses, for example, by helping companies with good ideas raise money. But it's hard to see how traders who place their orders one-thirtieth of a second faster than anyone else do anything to improve that social function."

In a study published in November 2012, Baron et al. [20] concluded that the profit of HFT firms, in buying and selling futures contracts are mainly derived from Opportunistic traders, but also from Fundamental (institutional) traders, Small (retail) traders, and Non-HFT Market Makers. Although HFT involves certain risks, they found unusually high average Sharpe ratios of a median of 4.5 for HFT firms. The authors also concluded that the fastest firms earn the highest profits.

HFT is a game changer-it challenges traditional understanding of risk. A financial markets' credibility depends on accurate pricing of risk. Accurately pricing risk depends on accurately understanding risk. The markets very existence is its lattice of rules and regulations. Therefore, the authority of the progenitor of rules and regulations is predicated not only on its ability to craft the market, but also, on its ability to read the market that it has crafted. The new phenomenaHFT-challenges the authority's historical understanding of the market, it ability to read the market, thereby, putting the authority's authority at risk. However, if HTF is simply changing who is making money, then, stringent regulation is unwarranted, as the purpose of such regulation would simply be to protect who is making money, as opposed to the value of the market. If, however, HFT is adversely affecting market 
value, by undermining trust in market stability, regulatory action must follow, but only up to, and not exceeding, the point at which risk can be understood and informed trading positions pursued. After all, the point of the market is value, not pre-designating the beneficiary of that value, ergo; understanding risk is not the same thing as eliminating risk. Therefore, proposed regulations should be weighed against adversely affecting the dynamism and substantial liquidity offered by HFT to the degree that dynamism and liquidity increase market value.

Possible regulations to control HFT may be divided into six groups:

- Taxes, taxation on financial transactions to discourage speculation and HFT.

- Delay, built-in latency in a bid that it has to be held for a period of time before it can be executed.

- Automatic trading halting (circuit breakers), with the purpose stopping the price of a share that moves too far away from a reference price.

- Market makers, requiring a commitment of market-makers to provide liquidity, regardless of the state of the market.

- Minimum requirements, adoption of minimum tick sizes, calibrated based on price and levels of liquidity, and/or a minimum resting period.

- Co-location facilities are made available on a non-discriminatory manner.

Criticisms against government HFT reports is that the reports overlook evidence pertinent to the most debated issues, such as the payments exchanges gives brokers to receive customer orders [21,22].

\section{The Difficulty with Evidence Being Considered?}

Reviewing HFT dynamics has limitations. The Hinesburg uncertainty principle offers possible enlightenment. In physics, the uncertainty principle states that the more precisely a particle position can be known the less precisely its momentum can be known. The analogy is this: HFT takes place more quickly than human analysis can follow, with computers inevitably taking over the market. Therefore, the effects of HFT can only be understood after the fact. In other words, to understand what is happening at any given moment in a market dominated by computer controlled HFT, HFT must be stopped and the results analyzed; i.e., the market must be stopped in order to understand what has taken place at any particular time, and, more importantly, to understand whether what has taken place at any particular time has benefitted the market. The founding purpose of exchanges was to allocate capital to its most productive uses, therefore, determining whether HFT supports that purpose should weigh heavily on any discussion concerning the future of HFT. Of course, nobody wants to bring the markets to a halt. Fortunately, there are alternatives.

The singular, most self-serving HFT market advantage is volatility. However, the picture is not complete, some studies $[11,23,24]$ find that HFT adds liquidity to the market by using market making and arbitrage strategies. There are several unanswered questions, here, where the most frequent issues pointed out are [25]:

- HFTs have no market making obligation. This can lead to a dearth of liquidity, especially in volatile market conditions.

- HFTs contribute little to the depth of the market because of the marginal size of their quotes. This can result in larger orders displacing many smaller orders and can affect the overall transaction costs.
- HFT quotes are hardly accessible because of the extremely short time in which liquidity is available as orders cancel within milliseconds.

The UK government study concluded, not surprisingly, that more long-term study needs to be done in order to improve the understanding of the effects of HFT. However, to be able to find evidence of how HFT affects the market, detailed and accurate data is necessary in order to enable risk-mapping. There is no dearth of data, but, first, it is necessary to request the models from HFT firms and the trading data from the exchanges. That data should be requested is, also not surprising, as, after all, in order to trade at all, HFT firms must apply for, and be granted, a permit.

HFT algorithms are short lived, with a life span commonly not exceeding more than 3-4 days. Therefore, in order to understand the effect of HFT, research need access to both the HFT models and the dates used, thereby allowing the researchers to test the models on real data in order to see how they work and how they affect the market. Many techniques to analyze HFT data already exists in other large, complex systems, such as weather and satellite systems. Only by getting the real models and the real data can scholars understand the real benefits and real risks with high-frequency trading.

\section{References}

1. The circuit breakers designed to restrict the large fluctuations in the price of shares in excess of an increase or decrease of 10 percent over a five minute period.

2. Jain PK (2005) Financial Market Design and the Equity Premium: Electronic versus Floor Trading. Journal of Finance 60: 2955-2985.

3. Clark CL (2010) Controlling risk in a lightning-speed trading environment Federal Reserve Bank of Chicago Financial Markets Group, Policy Discussion Paper Series PDP 1.

4. Andersen TG, Bollerslev T, Diebold FX, Vega C (2003) Micro Effects of Macro Announcements: Real-Time Price Discovery in Foreign Exchange. American Economic Review 93: 38-62.

5. Cao C, Hansch O, Wang X (2009) The Information Content of an Open LimitOrder Book. Journal of Futures Markets 29: 16-41.

6. O’Hara M (1995) Market Microstructure Theory. Blackwell Publishing, Oxford.

7. Pirrong C (2002) Securities Market Macrostructure: Property Rights and the Efficiency of Securities Trading. Journal of Law, Economics, \& Organization 18: $385-410$.

8. Foresight: The Future of Computer Trading in Financial Markets (2012) Final Project Report. The Government Office for Science, London.

9. Boehmer E, Fong K, Wu J (2012) International Evidence on Algorithmic Trading. Working Paper.

10. Haldane AG (2011) The race to zero.

11. Hendershott T, Riordan R (2011) Algorithmic Trading and Information. Working Paper.

12. Baron M, Brogaard J, Kirilenko A (2012) The Trading Profits of High Frequency Traders. Working paper.

13. Kirilenko A, Kyle AS, Samadi M, Tuzun T (2011) The Flash Crash: The Impact of High Frequency Trading on an Electronic Market. Working Paper.

14. Hendershott T, Riordan R (2012) Algorithmic Trading and the Market for Liquidity. Journal of Financial and Quantitative Analysis, forthcoming.

15. Hendershott T, Jones C, Menkveld AJ (2011) Does Algorithmic Trading Increase Liquidity? Journal of Finance 66: 1-33.

16. Flash Crash is an event on May 6th 2010 called, when the Dow Jones made it largest intraday loss when it lost $\$ 1$ trillion of market value within half an hour Knight Capital is a HFT firm that on August 12th 2012 lost \$ 440 million in 45 minutes due to a program bug. 
Citation: Brunzell T (2013) High-frequency Trading-to Regulate or Not to Regulate-That is the Question? Does Scientific Data Offer an Answer? J Bus \& Fin Aff 2:e121. doi:10.4172/2167-0234.1000e121

Page 4 of 4

17. Zhang F (2010) High-Frequency Trading, Stock Volatility, and Price Discovery. Working Paper.

18. Executive director of financial stability at the Bank of England.

19. Krugman P (2009) Rewarding bad actors. The New York Times (2nd Aug), ppA21.

20. Baron M, Brogaard J, Kirilenko A (2012) The Trading Profits of High Frequency Traders. Working paper.

21. Nathaniel P (2012) In Report, Speed Trades' Problems and Pluses. The New York Times (22th Oct ), ppB1.
22. The criticisms was forwarded by Joe Saluzzi co-founder of Themis Trading (an independent agency brokerage firm) and co-author of the book "Broken Markets: How High Frequency Trading and Predatory Practices on Wall Street are Destroying Investor Confidence and Your Portfolio.

23. Jovanovic B, Menkveld AJ (2011) Middlemen in Limit-Order Markets. Working Paper.

24. Hagströmer B, Norden L (2012) The Diversity of High Frequency Traders.

25. Chilistalla M (2011) High-frequency trading. Better than its reputation? Deutsche Bank Research. 